\title{
Williamson On the Margins of Knowledge: A Criticism
}

\author{
Ciro De Florio ${ }^{1}$ Vincenzo Fano ${ }^{2}(1)$
}

Accepted: 27 October 2020 / Published online: 13 November 2020

(c) The Author(s) 2020

\begin{abstract}
In this paper, we argue that Williamson's arguments against luminosity and the KK principle do not work, at least in a scientific context. Both of these arguments are based on the presence of a so-called "buffer zone" between situations in which one is in a position to know $p$ and situations in which one is in a position to know $\neg p$. In those positions belonging to the buffer zone $\neg p$ holds, but one is not in a position to know $\neg p$. The presence of this buffer zone triggers two types of sorites arguments. We show that this kind of argument does not hold in a scientific context, where the buffer zone is controlled by a quantitative measurement of the experimental error.
\end{abstract}

Keywords KK principle $\cdot$ Limits of knowledge $\cdot$ Luminosity $\cdot$ Measurement

\section{Introduction}

It is difficult to overestimate the importance that Williamson's Knowledge and its Limits (hereafter, $\mathrm{K} \& \mathrm{~L}$ ) had and still has in the philosophy community. As is well known, Williamson extensively argues against the classical analysis of knowledge as justified true belief. According to Williamson (2000, p. 6) "knowledge" is a mental state: sometimes we are in a position to know, i.e. "knowledge is a primitive kind of mental event." In this perspective, knowledge is a part of the world. However, K\&L is not only a "long argument" in favor of the conception that knowledge is a fundamental mental state; it contains legions of sub-arguments as well connected to crucial and very often provocative issues in the philosophy of knowledge.

Williamson's book is deeply rooted in a progressive program in philosophy that probably started with Hintikka's seminal Knowledge and Belief (see Hintikka 2010). Hintikka shows that philosophical reflection benefits from the powerful instrument of formal logic in order to adequately characterize fundamental concepts such as knowledge, belief, justification, and reliability. ${ }^{1}$ Moreover, the intended domains to which those very sophisticated logical frameworks apply usually belong to common sense knowledge. We believe,

\footnotetext{
1 See for instance Fagin et al. (2004).

Vincenzo Fano

vincenzo.fano@uniurb.it

1 Department of Philosophy, Università Cattolica di Milano, Milan, Italy

2 Department of Pure and Applied Sciences, Università Carlo Bo di Urbino, Urbino, Italy
} 
however, that in scientific contexts many of the most important problems in epistemology acquire a different structure. Does this mean that the entire debate in formal epistemology applied to everyday contexts must be abandoned? Of course not. But, on the other hand, formal epistemology, even its non-Bayesian part, could be implemented and extended if opened to the immense pool of scientific knowledge.

Here let us first define the two contexts: everyday knowledge and scientific knowledge. Common sense knowledge contexts involve instances of either perception or self-knowledge, and in such contexts, it is almost impossible to disregard the mental states and actions of the knower. Scientific contexts, on the other hand, seem to be different in that, while the beliefs and actions of scientists and researchers are an interesting topic of research in psychology and sociology of science, from a logical point of view they are not particularly relevant. Perhaps an example can help to clarify this issue. Take for instance "Hubble's principle", according to which "spacetime is dilating". (1) Our best scientific theories can justify either its truth or its falsehood. (2) Empirical data can entail that it must be formulated with a different constant of expansion. (3) The mathematical language in which it is formulated must respect certain a priori constraints, such as those of elementary arithmetic and differential geometry. (4) The inductive connection between astrophysical data and its formulation can be very complex and ambiguous etc. These all are epistemological questions. On the other hand, historical and sociological situations like the fact that Einstein did not at first accept Hubble's principle and that Hubble persuaded him with his empirical data are very interesting, but not within an epistemological context. ${ }^{2}$

Williamson builds on an externalist view of the mind, arriving at the reasonable consequence that knowledge is a mental state dependent on the external world. This is an interesting point of view if we are concerned with perception and common knowledge in general. However, when one speaks of the rational belief of a scientific community, one is not arguing about a peculiar relation between scientists' mind and the external world, and the same holds true for their knowledge. In other words, the notion of normativity of belief and knowledge has-in a scientific framework-a different meaning from what applied to everyday knowledge context. And this normativity is what we plan to investigate on the basis of our best scientific practices; that is, epistemology of natural sciences discusses those methodologies endowed with large empirical success. Of course, everyday and scientific knowledge are not altogether independent and a comparison between them is very interesting.

Behind the almost exclusive attention of epistemologists to everyday contexts most likely lies the assumption that, at the end of the day, scientific knowledge is only a peculiar kind of refined common sense knowledge. It could also be that some scholars believe that considering certain scientific practices as epistemological models-as proposed in the preceding paragraph - is a strong presupposition not epistemologically validated. In other words, some epistemologists wish to start with establishing which is, in general, the right epistemology and then apply it in different contexts, the scientific one included. ${ }^{3}$ We intend to show, on the contrary, that scientific contexts are essentially different from the common sense ones, at least in certain cases. Moreover, concerning the criticism of the idea of

\footnotetext{
${ }^{2}$ Of course, this is a simplification; as a referee rightly noticed, the interplay between data and their acceptance is much more complex and, sometimes, it could be relevant for the growth of scientific knowledge.

3 Here perhaps Hegel's criticism to Kant's epistemology (Encyclopedia, Section 10) is in order: to establish what is knowledge without knowing is like that schoolman who wish to learn swimming before entering the water!.
} 
taking good scientific practices as models, one can answer that perhaps to formulate a good epistemology without presuppositions is impossible and the success of empirical methods in natural sciences seems a good reason for building on those procedures.

In this vein, the aim of this article is to show that if one is assuming a notion of knowledge as it is presupposed by working scientists, a couple of Williamson's main arguments cannot be framed in the same form. In particular, we want to argue that Williamson's antiluminosity argument and margins of error argument against the KK principle cannot be devised if a standard notion of scientific and empirical knowledge is assumed. Of course, this does not prove that it is impossible to re-shape the original argumentative schema in order to adapt it to scientific scenarios; however, the burden of proof is on the opponent's shoulders.

The paper is organized in the following manner: in the next section we briefly summarize Williamson's anti-luminosity argument and show its inapplicability in a scientific context; in the Sect. 4 we present his specific argument against the KK principle. In the Sect. 3 , which is the core of the paper, we propose a different semantics for the margins of knowledge, and we show that one of Williamson's key principles can no longer be formulated.

\section{Anti-Luminosity}

Williamson defines a mental state (or a condition) luminous $^{4}$ as follows:

(Luminosity) Condition $\mathrm{C}$ is luminous iff for every case $\alpha$, if in $\alpha \mathrm{C}$ obtains, then in $\alpha$ one is in a position to know that $\mathrm{C}$ obtains (Williamson 2000, p. 95).

Where "to be in a position to know $p$ " is factive; that is, "to be in a position to know $p$ " is not a sufficient condition to know $p$, but if one is in a position to know $p$, then $p$ is true.

A paradigmatic example is a headache: suppose Mary has a headache; so, to acquire knowledge of her own headache Mary must do practically nothing; just consider that she has headache. Therefore, the headache seems luminous. The same, obviously, does not hold for other states, typically non-mental. Consider the presence of beer in the refrigerator. Of course, this condition is not luminous: Mary is not always in the position to know if there is beer in the refrigerator. Maybe she forgot whether there was beer and she must check it out. Indeed, Mary would be in a position to know whether there is beer in the refrigerator either if she were looking in the refrigerator, or if she reliably remembered to have put beer in the refrigerator, or she were in other similar situations.

Williamson's aim is to show that mental conditions are not luminous. To do this, he considers a peculiar example of a mental condition, that of feeling cold. ${ }^{5}$ Let us suppose, along with Williamson, that "one feels cold at dawn, very slowly warms up, and feels hot by noon" (Williamson 2000, p. 94). Without losing generality, we assume that "one" is "Mary". The interval between dawn and noon is divided in very small amounts of time, say, $m$-milliseconds intervals; more formally, we have $\alpha_{0}$, which is the case at dawn, and $\alpha_{n}$, which is the case at noon. Now, the salient facts are the following:

\footnotetext{
4 The literature on Williamson's discussion on luminousity is broad; see for instance: Brueckner and Fiocco (2002); Neta and Rohrbaugh (2004); Weatherson (2004); Ramachandran (2009); Srinivasan (2015).

5 Note that the proposed example comes from common sense knowledge and not scientific knowledge.
} 
(i)

(ii)

(iii)
In $\alpha_{0}$ Mary feels cold.

In $\alpha_{n}$ Mary does not feel cold.

During the process, Mary considers how cold or hot she feels, but the $m$ milliseconds interval is too small for her to be aware of the thermal difference between time $\mathrm{i}$ and time $\mathrm{i}+1$.

These facts are supposed to describe a quite common situation. Williamson argues that if feeling cold is a luminous condition then we get a contradiction. Therefore, by reduction, feeling cold is not a luminous state. Since the choice of the mental state is not relevant, this argument can be generalized to all similar cases of self-knowledge and beyond.

The first crucial premise of Williamson's argument is the following:

According to a luminosity defender, (A) could be justified by Mary's reliable introspection of her own feelings. In other words, (A) amounts to the luminosity of feeling cold. Moreover, Williamson assumes that:

If Mary knows that she feels cold in $\alpha_{i}$, then she feels cold in $\alpha_{i+1}$.

The defense of (B) can be articulated a bit more using the insight that knowledge requires safety. That is, if one knows $p$ in a given case, then $p$ is true in every similar ${ }^{6}$ case in which one believes that $p$. So, Mary knows that she feels cold in $\alpha_{i}$ and the content of this knowledge - that is, the fact that she feels cold - must be true in any case similar to $\alpha_{i}$ in which she believes she is feeling cold. But, by assumption (iii), the case $\alpha_{i+1}$ is impossible to discriminate from case $\alpha_{i}$. Therefore, Mary would believe that she feels cold in $\alpha_{i+1} \cdot{ }^{7}$

Now, let us examine how Williamson's reduction works. By assumption (i) and (A) we have that Mary knows that she feels cold in $\alpha_{0}$. But then (by (B)) we have that Mary feels cold in $\alpha_{1}$. Of course, she knows that she feels cold in $\alpha_{1}$. (That holds for principle (A)). But applying again (B), we derive that she feels cold in $\alpha_{2}$. And then the argument can be reiterated many times. In the end, however, we reach the case in which Mary feels cold at noon, which is against (ii) (see Steup 2009).

Since, according to Williamson, principle (B) is deeply rooted in our epistemic structure, the crucial premise of the reduction is principle (A), that is, the alleged luminosity of the mental states. (B) is not eliminable because every kind of knowledge must have a buffer zone in which, even if the situation changes a bit, the knower does not modify his/ her knowledge, since what happens is under the threshold of his/her awareness.

The logical engine of Williamson's argument is similar to a sorites paradox: there is a series of cases, each very similar to adjacent ones, that starts with a case where $\mathrm{C}$ clearly obtains (feeling cold at dawn) and ends with a case where $\mathrm{C}$ clearly does not obtain (feeling cold at noon). But the luminosity principle imposes that whenever $\mathrm{C}$ obtains, we are in a

\footnotetext{
6 "Similar" in the sense that Mary is not able to discriminate between the two states.

7 Note that (B) is based on the reasonable assumption that there is a buffer zone between being in a position to know $p$ and being in a position to know $\neg p$. An anonymous referee correctly notes that this is a consequence of the so-called "safety condition" in epistemology defended by Williamson himself (2000, p. 147). For an alternative no-luck strategy see Nozick's (1981).
} 
position to know if $\mathrm{C}$ obtains. Moreover, knowledge must be safe, that is, if we know that $\mathrm{C}$ obtains, $\mathrm{C}$ obtains in all similar cases. But then $\mathrm{C}$ must obtain in all similar cases, which is contrary to the idea that through very similar (and indistinguishable) cases we get to a very different case, in which $\mathrm{C}$ does not obtain at all. The main point of Williamson's argument is that in every kind of knowledge there are situations which are completely similar from our subjective point of view, even if something is objectively changed. And this issue, expressed by (B), is incompatible with luminosity, expressed by (A).

If Williamson's argument is sound, it should be applicable to any mental state; that is, it should hold also for that peculiar mental state which, according to Williamson, is knowledge. If knowledge were luminous, then if we know that $p$, we should be in a position to know that we know that $p$. This principle is known in literature as the KK principle, and we will see in the following how Williamson argues against it.

Here it is in order to consider again the difference between common sense and scientific knowledge. Williamson's argument is based on what he calls a buffer between to be in a position to know $p$ and the falsehood of $p$. This is a margin of error zone, one in which $p$ is no longer true, but we are not in a position to know that $\neg p$. This zone is epistemological, that is, it concerns the situation of the knower. But in a scientific context the situation is quite different.

In Williamson's example: one builds knowledge on a certain inner state, that is, Mary's cold feeling. But what would happen in a similar situation if we apply his argument to a scientific context?

Let us consider what could be a scientific translation of (A)'s antecedent: "Mary feels cold in $\alpha_{i}$ ". In the case of scientific practice, the possibly luminous state is not a simple inner feeling, but the repetition of many situations $\alpha_{i}$ with many different subjects. And the result of this experiment can be so described:

$\left(\mathrm{a}_{\mathrm{i}}\right)$

A randomized sample of people in situation $\alpha_{i}$ the most part of times judges that it is cold.

The consequent of the original (A) would be that in state $\alpha_{i}$ Mary knows that she feels cold. In the new framework, one can say that:

$\left(\mathrm{A}_{\mathrm{i}}\right)$ People in situation $\alpha_{i}$ feel cold.

The difference between $\left(\mathrm{a}_{\mathrm{i}}\right)$ and $\left(\mathrm{A}_{\mathrm{i}}\right)$ is that the former refers to an experimental sample, whereas the latter is a generalization to the whole population.

Let us emphasize that in a scientific context it is not necessary to introduce the operator "know", as Williamson does in the case of Mary, since the result of an experiment $\left(\mathrm{a}_{\mathrm{i}}\right)$ justifies a given statement $\left(\mathrm{A}_{\mathrm{i}}\right)$, not the knowledge by someone of that statement. At first sight our choice seems a bit strange, since Williamson's argument concerns knowledge. But it is not so obvious, as many scholars maintain, that knowledge is a statement preceded by a subjective knowledge operator. The latter is actually a "representation" of a knowledge. In empirical science, knowledge instead is a true justified statement. For this reason, we omit the knowledge operator. Nevertheless, if one reintroduces the knowledge operator, the argument is still valid. In other terms, we can say that: If $\left(\mathrm{a}_{\mathrm{i}}\right)$ then $\left(\mathrm{A}_{\mathrm{i}}\right)$.

Note that, in the new context, $\left(\mathrm{A}^{\prime}\right)$ expresses luminosity in science, which is a completely reliable inference from an experimental situation to a truth. 
Now we move to the antecedent of (B), that is the same as the consequent of (A). Therefore, the antecedent of $\left(\mathrm{B}^{\prime}\right)$ will be:

$\left(\mathrm{A}_{\mathrm{i}}\right)$ People in situation $\alpha_{i}$ feel cold.

The consequent of (B) instead was: "Mary feels cold in situation $\alpha_{i+1}$ ". The analogous situation in the new framework will be:

$\left(a_{i+1}\right) \quad$ The majority of people in situation $\alpha_{i+1}$ the most part of times judges that it is cold.

Therefore:

$\left(\mathrm{B}^{\prime}\right)$

If $\mathrm{A}_{\mathrm{i}}$ then $\mathrm{a}_{\mathrm{i}+1}$.

At this point we must translate (i)-(ii) in the new language. This is straightforward:

It is easy to show that from $\left(\mathrm{A}^{\prime}\right),\left(\mathrm{B}^{\prime}\right)$, and from (i') to (ii') it is possible to deduce the contradictory of (ii'), in a similar way to what done in the case proposed by Williamson:

The majority of people in $\alpha_{n}$ the most part of time judges that it is cold.

Therefore, at first sight, it seems that Williamson's argument holds true even in a scientific context. However, the issue deserves more attention.

The most controversial assumption of this new argument is $\left(\mathrm{B}^{\prime}\right)$. To better understand it, we present $\left(\mathrm{B}^{\prime}\right)$ in an unpacked form:

(B') If people in situation $\alpha_{i}$ feel cold, then the majority of people in situation $\alpha_{i+1}$ the most part of times judges that it is cold.

Remember that in the case presented by Williamson, the justification of (B) was (iii).

(iii) During the process Mary considers how cold or hot she feels, but the $m$ milliseconds interval is too small for her to be aware of the thermal difference between time $\mathrm{i}$ and time $\mathrm{i}+1$.

The analogous situation for (iii) in the new context would be:

(iii') During each repetition of the process people consider how cold and how hot they feel, but the $m$ milliseconds of interval between situation $\alpha_{i}$ and situation $\alpha_{i+1}$ is for the majority of people the most part of times too small to appreciate any thermal difference.

We must now establish whether (iii') is reasonable in an experimental contest.

Before discussing the validity of (iii'), let us remember a bit of measurement theory. To have a comparative scale, like the one we are involved with here, transitivity of comparative judgments is a necessary condition. That is, a condition of this kind must hold true: 
(T) If a subject judges $\alpha_{i}$ not colder than $\alpha_{j}$ and $\alpha_{j}$ not colder than $\alpha_{k}$, then s/he must judge $\alpha_{i}$ not colder than $\alpha_{\mathrm{k}}$.

It is evident that the set of judgements on which our experiment is based does not respect (T) ${ }^{8}$ Indeed, we have chosen the judgements of our subjects so that they experience confusion between two neighboring situations. In experimental contexts, if (T) does not hold, scientific investigation is not allowed involving comparison. ${ }^{9}$ In other words, to apply a comparative scale, transitivity between judgements is required. ${ }^{10}$ This means that in the case of non-transitive judgements, at best we can use a nominal classification, that is sentences of the kind "people feel cold" and "people do not feel cold". In a reasonable theory of measurement that uses a comparative scale, like the present one, statements like (iii') and $\left(\mathrm{B}^{\prime}\right)$ are devoid of cognitive meaning.

A defender of Williamson's perspective could object to our argument that a comparative scale is not necessary. Indeed, all judgements of the involved subjects are either of the form "people feel cold" or "people do not feel cold". Therefore, the violation of transitivity would not block Williamson's argument. It seems to us that without a comparative scale, Williamson's argument does not work adequately. Moreover, even a nominal scale has its necessary pre-conditions. For, the necessary condition to apply a so-called nominal scale is that each item is ascribed to only one scientific name. To understand better this point, let us consider again $\left(\mathrm{B}^{\prime}\right)$ :

$\left(\mathrm{B}^{\prime}\right)$ If people in situation $\alpha_{i}$ feel cold, then the majority of people in situation $\alpha_{i+1}$ the most part of times judges that it is cold.

In this sentence two kinds of stimuli appear: $\alpha_{i}$ and $\alpha_{i+1}$. By hypothesis the majority of people most parts of time is not able to distinguish between them, therefore they say in both cases that they feel cold. In his deduction Williamson applies (B') again and again, but even if his notion of the safe or buffer zone would compel him a priori to transmit the label "cold" along the series of $\alpha_{i}$ 's, empirically in order to be epistemologically possible to speak of a nominal scale-such as "cold", "not cold"-each item must belong to only one of the two labelled sets. In other terms, in a scientific nominal scale there is no buffer zone: each $\alpha_{i}$ either is cold or it is not cold. Experimentally, if a certain $\alpha_{i}$ is ascribed the most part of time by the majority of people to the label "cold" it is cold and vice versa. On the contrary, if it happens that $\alpha_{i}$ is ascribed exactly half of the times to "cold" and half of the time to "not cold", it is not possible to say either that is cold or that it is not cold.

Note that Williamson's buffer zone in scientific practice concerning measurement of mental features disappears. That is, in measuring the mind, to take into account the sensitivity of the subject, we repeat many times the experiment with many different subjects. Moreover, to use both a nominal and a comparative scale, the experimental reports of the subjects' judgements must respect certain rules, that is, respectively, dichotomicity and transitivity. If these rules do not hold, measurement and, consequently, experiments are not possible. In other terms, if judgements are neither dichotomous nor

\footnotetext{
${ }_{8}$ In (T) let us substitute $\mathrm{a}_{\mathrm{i}}$ with $\mathrm{a}_{1}, \mathrm{a}_{\mathrm{j}}$ with $\mathrm{a}_{2}$ and $\mathrm{a}_{\mathrm{k}}$ with $\mathrm{a}_{3}$. Then (T)'s antecedent is true, whereas (T)'s consequent is false.

9 This is well clarified in Michell (1997, chap. 5).

${ }^{10}$ Indeed, a form of probabilistic weak transitivity is enough (Twersky 2004). But the judgements we are considering violate even this weaker form.
} 
transitive, we are not in a position to apply $\left(\mathrm{A}^{\prime}\right)$, which is scientific luminosity. But this inapplicability does not mean that $\left(\mathrm{A}^{\prime}\right)$ is not true. This consequence does not mean that we are persuaded that luminosity holds in scientific contexts. Our point is much more modest; only that in scientific contexts this kind of sorites' argumentation is not relevant.

This seems enough to show the difference between common sense knowledge of internal states, where Williamson's argument seems compelling, and scientific contexts, where the situation is quite different. But in the next section we will see how Williamson applies this argument to knowledge as a mental state.

\section{Against the KK Principle}

Chapter 5 of $\mathrm{K} \& \mathrm{~L}$ is dedicated to arguing against the so-called KK principle. Axiom 4 of modal systems states that if it is necessary that $p$, then it is necessary that it is necessary that $p(\square p \rightarrow \square \square p)$. It is a logical routine to show that $\mathbf{4}$ holds only in frameworks in which the accessibility relation is transitive (and vice versa). Applied to epistemic scenarios, axiom 4 is called the "KK principle": if Jane knows that snow is white then Jane knows that she knows that snow is white.

What follows is a brief recap of Williamson's argument. But first, let us fix the language. The argument is couched in propositional logic enriched by the knowledge operator $\mathrm{K}$; $\mathrm{K}$ is regimented by:

Necessitation Rule: If $p$ is a theorem of $\Gamma$, then so is $\mathrm{K} p$.

Distribution Axiom: $\mathrm{K}(p \rightarrow q) \rightarrow(\mathrm{K} p \rightarrow \mathrm{K} q)$.

The axiom $\mathbf{T}$ :

(T)

$\mathrm{K} p \rightarrow p$

Momentarily we do not accept $\mathbf{4}$, that is $\mathrm{KK}$, since it is the object of our discussion. We can further use subscripts in order to represent schematic propositional variables, that is, if $p_{1}$ means that the table is $1 \mathrm{~m}$ long, we can write $p_{\mathrm{n}}$ to indicate that the table is $n$ meters long, since it is not relevant for the argument we can neglect the unit of measurement.

Say Jane looks at a distant tree. Her evaluation of the height of the tree from such a big distance cannot be very precise. We make the hypothesis that her error is of 1 of some length unit. Hence her evaluation is $h \pm 1$ in the chosen measurement unit. We assume that the results of Jane evaluations are natural numbers only. She knows how big her error might be. Moreover, if "e" is her evaluation, Jane knows that the tree is neither "10e" high, nor "0e" high.

Let us assume that the height of the tree is a certain value $t$; therefore, $h_{t}$ is the true proposition that says that the tree is $t$ high. The first principle (margins of error) states that:

$$
\mathrm{K}\left(\mathrm{K} \neg \mathrm{h}_{\mathrm{n}} \rightarrow \neg\left(\mathrm{h}_{\mathrm{n}+1}\right)\right)
$$

We omit the subscript "J" from all of the $\mathrm{K}$ operators, since that the knowledge always 
belongs to Jane is understood. The contrapositive of (1) is obviously Jane's knowledge of " $\mathrm{h}_{\mathrm{n}+1} \rightarrow \neg \mathrm{K} \neg \mathrm{h}_{\mathrm{n}}$ ". That is, Jane knows that "if the tree is $\mathrm{n}+1$ high, then Jane would not know that it is not $\mathrm{n}$ high". The justification of the latter is the following. ${ }^{11}$ Let us consider the set $\mathrm{W}$ of all possible worlds accessible to Jane where the tree is $\mathrm{n}+1 \mathrm{high}$; in order that (1) be true, in each world belonging to $\mathrm{W}$ " $\neg \mathrm{K} \neg \mathrm{h}_{\mathrm{n}}$ " must be true as well. For " $\neg \mathrm{K} \neg \mathrm{h}_{\mathrm{n}}$ " to be true, from each world belonging to $\mathrm{W}$, there must be at least one world where $h_{n}$ holds true. In each one of the $\mathrm{W}$ worlds, Jane looks at the tree and evaluates its height. Since the tree is $n+1$ high, the result of her evaluation will be a number belonging to the set $\{n$, $\mathrm{n}+1, \mathrm{n}+2\}$. Therefore, her evaluation can be $n$. Then there is at least one world-related to each world belonging to $\mathrm{W}$-in which $h_{n}$. From this follows that " $\neg \mathrm{K} \neg \mathrm{h}_{\mathrm{n}}$ " is true.

But from (1), by distributivity of K, we get: $\mathrm{KK} \neg \mathrm{h}_{\mathrm{n}} \rightarrow \mathrm{K} \neg\left(\mathrm{h}_{\mathrm{n}+1}\right)$

Now, (2) is a schema since it contains the (meta-)variable "n." Well, let us suppose, as already said, that Jane is reasonably certain that the tree is not 0 high. So,

But if knowledge was luminous, Jane should know that she knows that the tree is not 0 high. And this is precisely the content of the KK principle. So, for reductio:

Let us consider the schema (2); by instantiating n with "0", we have:

$\left(2^{\prime}\right)$ is a sentence, not a scheme; by modus ponens (and a little bit of arithmetic), from ( $\left.2^{\prime}\right)$ and (4) we obtain:

This brief deduction can be obviously re-iterated, obtaining then as a list the following:

But among those propositions there is also $\mathrm{K} \neg\left(\mathrm{h}_{\mathrm{t}}\right)$, which by factivity $(\mathbf{T})$ entails $\neg \mathrm{h}_{\mathrm{t}}$. The height of the tree is $\mathrm{t}$ and so there is a contradiction with our assumption that the tree is $\mathrm{t}$ high.

According to Williamson the weak assumption in this proof is the $\mathrm{KK}$ principle. Indeed, to deny $\mathbf{T}$, that is factivity, seems worse than to deny KK. The only further possibility is to

\footnotetext{
11 Williamson's presentation of this point is quite difficult to understand. This seems a reasonable interpretation.
} 
not accept (1), that is, Jane's awareness of her sight limitations. Perhaps in a non-scientific context, this could be a reasonable alternative. But we are applying the argument to scientific knowledge, that is, to experiment; and the experimentalist is supposed to know the experimental errors of her measurement.

\section{Luminous Intervals}

In this section we want to argue that Williamson's margins argument does not work for scientific knowledge; as previously said, this would introduce a sort of discontinuity in his treatment of knowledge: the case of everyday knowledge has to be characterized following some principles and abandoning others (for instance, the famous KK principle). However, because in other regions of knowledge things work differently, principles we abandoned for everyday knowledge can be included again in our theoretical setting.

Let us consider a measurement, as, for instance, that of length by means of a rod. It is clear that any experimental method-considered in a certain laboratory setting - has a superior threshold of resolution. For instance, it is not possible to determine the length of a stick by means of our rod with a resolution smaller than " 1 " measured in a suitable measurement unit. This means that if a stick either increases or decreases 1 unit, our rod is not able to register the change. With a notation similar to the preceding one, let us indicate the schema "a stick length is $n$ " with " $\mathrm{H}_{\mathrm{n}}$ ". However, there is no scientific measurement that has the form $\mathrm{H}_{\mathrm{n}}$, but on the contrary, has the form $\mathrm{H}_{\mathrm{n} \pm \mathrm{j}}$, since any scientific instrument has its sensibility. The intended meaning of $\mathrm{H}_{\mathrm{n} \pm \mathrm{j}}$ is that the length read on the rod has the value $n$, with an accuracy of plus or minus $j$.

While the discussion of this experimental situation can be articulated at length, since a measurement must be repeated many times and many other sources of uncertainty are normally involved, due to causes different from the resolution of the instrument, in this context, the consideration of resolution as a source of uncertainty is enough for our argumentation.

Of course, the epistemological reasons for the existence of the range $\mathrm{j}$ are well-known by scientists and philosophers of science: this range depends, essentially, on the fine tuning of our instruments and on the perturbative experimental conditions. And it is well known as well that those limitations cannot be eliminated. It goes without saying that with the passing of time our technological precision increases more and more, but our investigation of scientific knowledge must be applied to a given cognitive situation when resolution of our instruments reaches a certain threshold. Moreover, better instruments will produce the same condition at a different level of resolution; therefore, from an epistemological point of view the situation with better instruments would be similar.

Now, an advocate of Williamson's argument could accept our gloss on the scientific approach to measurement and recast principle (1) in these new clothes:

$(1 *)$ $\mathrm{K}\left(\mathrm{K} \neg \mathrm{H}_{\mathrm{n}} \rightarrow \neg\left(\mathrm{H}_{\mathrm{n}+\mathrm{j}}\right)\right)$

Where the operator " $K$ " refers to the knowledge of the experimenter. Remember that $\left(1^{*}\right)$ is the contrapositive of " $\mathrm{K}\left(\mathrm{H}_{\mathrm{n}+\mathrm{j}} \rightarrow \neg \mathrm{K} \neg \mathrm{H}_{\mathrm{n}}\right)$ ". But within the most interesting cases of experimental contexts the sentence " $\neg \mathrm{K} \neg \mathrm{H}_{\mathrm{n}}$ " is meaningless, since the knowledge of the experimenter involves necessarily the uncertainty due to the resolution of her rod. For this reason $(1 *)$ must be replaced by: 
$\left(1^{\circ}\right)$

$\mathrm{K}\left(\mathrm{H}_{\mathrm{n}+\mathrm{j}} \rightarrow \neg \mathrm{K} \neg \mathrm{H}_{\mathrm{n} \pm \mathrm{j}}\right)$

Let us emphasize that the subjective knowledge of the experimenter has margins, whereas reality has no margins. For this reason, the resolution appears in the consequent of $\left(1^{\circ}\right)$ and not in the antecedent.

At this point we must investigate whether $\left(1^{\circ}\right)$ is true. To be true $\left(1^{\circ}\right)$, in all worlds accessible to the experimenter where the stick is $\mathrm{n}+\mathrm{j}$ long-let us call this set $\mathrm{W}_{-}$, the experimenter must not know that the stick is not $\mathrm{n} \pm \mathrm{j}$ long, that is in each world belonging to $W$ there must be an accessible world where $h_{n \pm j}$ is true. Now, if the experimenter measures the length of the stick in one of these worlds, she will find either $n$ or $n+j$ or $n+2 j$, because, if the stick is $n+j$ long, the result will be $(n+j) \pm j$ Therefore, from each world were $\mathrm{H}_{\mathrm{n}+\mathrm{j}}$, there is an accessible world in which $\mathrm{H}_{\mathrm{n} \pm \mathrm{j}}$. Hence $\left(1^{\circ}\right)$ is true.

From $\left(1^{\circ}\right)$ one can derive: $\mathrm{KK} \neg \mathrm{H}_{\mathrm{n} \pm \mathrm{j}} \rightarrow \mathrm{K} \neg \mathrm{H}_{\mathrm{n}+\mathrm{j}}$

Evidently the experimenter knows that the length is not 0 :

Applying KK: $\mathrm{KK} \neg \mathrm{H}_{0 \pm \mathrm{j}}$

Substituting in the scheme $\left(2^{\circ}\right) \mathrm{n}=0$, we have: $\mathrm{KK} \neg \mathrm{H}_{0 \pm \mathrm{j}} \rightarrow \mathrm{K} \neg \mathrm{H}_{0+\mathrm{j}}$

From $\left(4^{*}\right),\left(3^{\circ}\right)$, Modus ponens and KK we deduce: $\mathrm{KK} \neg \mathrm{H}_{\mathrm{j}}$

At this point there is no possible substitution for $\mathrm{n}$ in $\left(2^{\circ}\right)$ such that its antecedent becomes identical to $\left(5^{*}\right)$ and Williamson's argument is blocked.

But a defender of Williamson's perspective could rebut our argument attempting to justify:

$$
\mathrm{K}\left(\mathrm{H}_{\mathrm{n}} \rightarrow \neg \mathrm{K} \neg \mathrm{H}_{\mathrm{n}+\mathrm{j}}\right)
$$

The justification of $\left(1^{*}\right)$ could be that if the length of the stick is $H_{n}$, then the measurement error $\mathrm{j}$ is such that the experimenter can actually measure $\mathrm{H}_{\mathrm{n}+\mathrm{j}}$. From $\left(1^{*}\right)$ one can deduce:

But again, it is not possible to substitute any value to $n$ in $\left(2^{*}\right)$ to obtain that its antecedent is identical to $\left(4^{*}\right)$. And Williamson's argument is blocked even in this perspective.

Here a brief reflection on the reason why Williamson's argument is blocked is in order. The justification of all forms of $(1)-\left(1^{*}\right)$ and $\left(1^{\circ}\right)$-is based on the real length of the stick 
in the antecedent and on experimenter's knowledge in the consequent. But, and this is crucial, reality has no margins, whereas knowledge does have margins. In a common sense knowledge context one can "forget" these margins - as done by Williamson-but not in an experimental one. The presence of margins of error in knowledge sentences blocks the sorites' chain.

Summing up: in scientific practice, measurement judgements are always in the form: $\mathrm{X}_{\mathrm{n} \pm \mathrm{j}}$; Williamson's reductio against $\mathrm{KK}$ exploits a form of regression principle which hinges on a series of very small increments under the threshold of observability. However, in an experimental context, the degree of resolution of the instrument is essential to the representation of our knowledge. And the introduction of the margins in our knowledge blocks Williamson's sorites' argument.

\section{Concluding Remarks}

In contemporary epistemology, the majority of investigated cases come from common sense knowledge. However, it is not evident that what holds true for external perception or for the self-knowledge of our mental states is suitable either for experimental sets or for the acceptance of highly abstract scientific theories.

Williamson's book K\&L is built on everyday knowledge examples. One of the main theses of the book is that we are homeless from a cognitive point of view, that is, that there is no place where we can be completely sure of our knowledge. Although this is a very reasonable thesis, since Williamson believes that knowledge is a peculiar mental state defined in an externalist framework, anti-luminosity compels him to deny the validity of the KK principle, else luminosity would reappear. However, if one thinks that experimental knowledge has a peculiar form of normativity, the problem of luminosity disappears. In a scientific context, knowledge is not a mental state but the satisfaction of a set of reasonable criteria determined by our best scientific practices. For this reason, knowledge is an altogether conscious endorsement of either one or more sentences, so Williamson's argument against $\mathrm{KK}$ is not so straightforward.

Williamson couches an argument against luminosity in a sorites form. But we have shown that when the same argument is applied in an experimental situation, it is no longer valid. This does not mean that there are luminous scientific situations, but it does show that this is not a good road for proving non-luminosity in a scientific context.

In the fifth chapter of L\&K, Williamson applies a similar sorites argument to prove the falsehood of KK. We have again shown that when we transfer his reasoning to a case of scientific measurement, the sorites is not triggered; hence this refutation of the KK principle does not work.

We conclude that a good amount of progress in epistemology can be made if we take into consideration the difference between everyday knowledge contexts and scientific ones.

Funding Open access funding provided by Università degli Studi di Urbino Carlo Bo within the CRUICARE Agreement.

Open Access This article is licensed under a Creative Commons Attribution 4.0 International License, which permits use, sharing, adaptation, distribution and reproduction in any medium or format, as long as you give appropriate credit to the original author(s) and the source, provide a link to the Creative Commons licence, and indicate if changes were made. The images or other third party material in this article are included in the article's Creative Commons licence, unless indicated otherwise in a credit line to the 
material. If material is not included in the article's Creative Commons licence and your intended use is not permitted by statutory regulation or exceeds the permitted use, you will need to obtain permission directly from the copyright holder. To view a copy of this licence, visit http://creativecommons.org/licenses/by/4.0/.

\section{References}

Brueckner, A., \& Fiocco, M. O. (2002). Williamson's anti-luminosity argument. Philosophical Studies, 110(3), 285-293.

Fagin, R., Halpern, J. Y., Moses, Y., \& Vardi, M. (2004). Reasoning about knowledge. New York: MIT Press.

Hintikka, J. (2010). Logic and belief. An introduction to the logic of the two notions. Cornell: Cornell University Press.

Michell, J. (1997). An introduction to the logic of Psychological measurement. New York: Psychology Press.

Neta, R., \& Rohrbaugh, G. (2004). Luminosity and the Safety of Knowledge. Pacific Philosophical Quarterly, 85(4), 396-406.

Nozick, R. (1981). Philosophical explanations. Harvard: Harvard University Press.

Ramachandran, M. (2009). Anti-luminosity: Four unsuccessful strategies. Australasian Journal of Philosophy, 87(4), 659-673.

Srinivasan, A. (2015). Are we luminous? Philosophy and Phenomenological Research, 90(2), 294-319.

Steup, M. (2009). Are mental states luminous? In D. Pritchard \& P. Greenough (Eds.), Williamson on knowledge (pp. 217-236). Oxford: Oxford University Press.

Twersky, A. (2004). The intransitivity of preferences. In E. Shafir (Ed.), Preferences, belief, and similarity (pp. 433-462). Cambridge: MIT Press.

Weatherson, B. (2004). Luminous margins. Australasian Journal of Philosophy, 82(3), 373-383.

Williamson, T. (2000). Knowledge and its limits. Oxford: Oxford University Press.

Publisher's Note Springer Nature remains neutral with regard to jurisdictional claims in published maps and institutional affiliations.

Ciro De Florio is Associate Professor of Logic and Philosophy of Science at the Department of Philosophy, Università Cattolica, Milan. He is interested in formal approaches to classical philosophical topics, especially ontological and epistemological ones. He worked on philosophy of logic and mathematics (higher order logics) and on the philosophical relevance of the Tarskian concept of truth. Presently, he is dealing with models of temporal logic, systems of pragmatic logic and the characterization of the nexus of logical consequence in terms of conceptual grounding.

Vincenzo Fano is Full Professor of Logic and Philosophy of Science at Urbino University. He is also President of the Italian Society for Logic and Philosophy of Sciences and member of the Academie de Philosophie de la Science. Hìs main research interest is the Philosophy of physics. He worked in the philosophy of mind as well and in the history of science. 